TOTOBUANG

Volume $9 \quad$ Nomor 2, Desember 2021 Halaman 315-329

\title{
NILAI MORAL DALAM TOKOH CERITA BUAYA LEARISA KAYELI: KAJIAN SASTRA ANAK \\ (Moral Value in Character of Learisa Kayeli's Crocodile Story: A Study of Children's Literature)
}

\author{
Dudung Abdulah \\ Kantor Bahasa Provinsi Maluku \\ Kompleks LPMP Maluku, Wailela, Rumah Tiga, Teluk Ambon, Ambon, Maluku 97234 \\ Pos-el: abdulahdudung008@gmail.com
}
Diterima: 1 Februari 2021; Direvisi: 16 September 2021; Disetujui: 5 Oktober 2021
doi: https://doi.org/10.26499/ttbng.v9i1.327

\begin{abstract}
This study aims to discover the moral value in character of Learisa Kayeli's Crocodile story written and developed by Asrif. Literary studies talking about children's literature through Maluku folklore are still not found in scientific journals. Therefore, the theory used in this study is the children's literature theory of Burhan Nurgiyantoro. The research method used descriptive method of content analysis. This study describes the qualifications and disclosure of the character from the story as an introduction in interpreting the moral values. This story was chosen because (1) it has never been examined using children's literature theory; (2) the important characters are played by animal characters and result in more readers' imagination compared to stories with human characters; (3) this story is intended for children especially for the fourth, fifth, and sixth graders; (4) it has a complete storyline; and (5) it is printed Maluku folklore written in Indonesian and went through digitalization process. This study concludes that there are seven moral values conveyed by the author in character of Learisa Kayeli's Crocodile story, namely: (1) do not be afraid to defend the truth or to quell tyranny even though life is at stake in order to create a harmonious and peaceful life; (2) appreciate the one who has contributed in (saving) your life in order to establish eternal brotherhood until the end of life; (3) do not disturb the peace of other people's lives so that your lives remain fortune; (4) never give up in trying to do something so that your dreams can be achieved; (5) make good friends with others so that you may be accepted by anyone and anywhere including in any new environment; (6) be patient in solving any obstacles in life so you can cherish other people; and (7) be wise to the surrounding environment in order to create a healthy natural balance so that it can provide benefits for mankind.
\end{abstract}

Keywords: Moral Value, Character, Children's Literature.

\begin{abstract}
Abstrak
Kajian ini bertujuan menelusuri nilai moral dalam tokoh cerita rakyat Maluku berjudul Buaya Learisa Kayeli yang ditulis dan dikembangkan oleh Asrif. Kajian sastra yang mengangkat tentang sastra anak melalui cerita rakyat Maluku masih belum ditemukan dalam karya ilmiah. Teori yang digunakan dalam kajian ini adalah teori sastra anak. Metode penelitian yang digunakan adalah metode deskriptif analisis. Kajian ini mendeskripsikan kualifikasi dan pengungkapan watak tokoh cerita sebagai pengantar dalam menafsirkan nilai moral yang terkandung di dalamnya. Cerita ini dipilih karena (1) belum pernah dikaji melalui kajian sastra anak; (2) para tokoh penting diperankan oleh karakter binatang sehingga nilai fantasinya lebih tinggi daripada cerita dengan tokoh manusia; (3) cerita ini diperuntukkan bagi anak-anak terutama kelas 4, 5, dan 6; (4) memiliki cerita yang utuh; dan (5) merupakan cerita rakyat Maluku yang sudah dibukukan dan sudah berbahasa Indonesia bahkan sudah mengalami proses digitalisasi. Hasil kajian menunjukkan bahwa ada tujuh nilai moral yang disampaikan pengarang dalam tokoh cerita Buaya Learisa Kayeli, yaitu (1) janganlah takut membela kebenaran/menumpas kezaliman meskipun nyawa menjadi taruhannya supaya tercipta kehidupan yang harmonis dan tenteram; (2) hargailah orang yang telah berjasa dalam (menyelamatkan) hidupmu supaya terjalin persaudaraan yang abadi sampai akhir hayat; (3) janganlah suka mengganggu ketenangan hidup orang lain supaya tidak bernasib buruk di kemudian hari; (4) jangan pernah menyerah dalam berusaha supaya impianmu bisa tercapai; (5) berperangailah dengan baik terhadap orang lain supaya kamu bisa diterima oleh
\end{abstract}


siapa pun dan di mana pun termasuk di lingkungan baru sekali pun; (6) bersabarlah dalam menghadapi rintangan kehidupan supaya buah dari kesabaran itu bisa bermanfaat bagi orang lain; dan (7) bersikap bijaklah terhadap lingkungan sekitar supaya tercipta keseimbangan alam yang sehat sehingga bisa memberikan keuntungan bagi umat manusia.

Kata-kata kunci: Nilai Moral, Tokoh Cerita, Sastra Anak

\section{PENDAHULUAN}

Menurut Sumardjo dan Saini (1988:3), sastra merupakan ungkapan pribadi manusia yang berupa pengalaman, pemikiran, perasaan, ide, semangat, dan keyakinan dalam suatu bentuk gambaran konkret yang membangkitkan pesona dengan alat bahasa. Adapun Quinn (1992 dalam Sarumpaet, 2017:1) seorang ahli dari Barat mengatakan bahwa sastra adalah tulisan yang khas dengan pemanfaatan kata yang khas, tulisan yang beroperasi dengan cara yang khas dan menuntut pembacaan yang khas pula. Dari kedua pendapat tersebut, dapat disimpulkan bahwa sastra adalah bahasa yang disampaikan baik secara lisan maupun tulisan yang memiliki kekhasan sebagai hasil dari pengalaman, pemikiran, perasaan, ide, semangat, dan keyakinan yang secara nyata bisa membangkitkan pesona.

Jika dilihat dari sudut pandang target sasarannya, sastra Indonesia diklasifikasikan menjadi tiga kategori, yaitu sastra anak, sastra remaja, dan sastra dewasa. Salah satu genre sastra anak adalah sastra tradisional. Sastra tradisional merupakan cerita rakyat yang telah mentradisi, tidak diketahui kapan mulainya, dan dikisahkan turun temurun secara lisan (Nurgiyantoro, 2019:25). Ada banyak subgenre cerita rakyat yang berkembang di Indonesia, antara lain: mitos, legenda, cerita binatang, dongeng, dan cerita wayang.

Selain sebagai alat untuk memberikan hiburan, karya sastra khusus sastra anak apa pun genrenya dan/atau apa pun subgenrenya memiliki pesan moral yang terkandung di dalamnya. Teks-teks kesastraan diyakini mengandung suatu "ajaran" karena tidak ada pengarang yang menulis tanpa pesan moral (Nurgiyantoro,
2019:68). Sudah menjadi tradisi orang tua zaman dahulu memanfaatkan pesan moral yang disampaikan oleh pengarang dalam suatu cerita sebagai media untuk mendidik anak. Dalam hal ini penulis menyebutnya nilai moral dalam cerita rakyat.

Sastra anak tradisional, dalam hal ini cerita rakyat yang berkembang di Indonesia, salah satunya dapat dijumpai di Maluku. Maluku merupakan salah satu provinsi di Indonesia yang kaya akan bahasa daerah. Puluhan bahasa daerah yang ada di Maluku melahirkan banyak cerita rakyat di dalamnya. Pada dasarnya, cerita rakyat Maluku dikisahkan turun temurun secara lisan dari nenek moyang kepada generasi mudanya. Namun, seiring perkembangan zaman, minat generasi muda dalam melestarikan cerita rakyat semakin rendah. Hal ini dikuatkan dengan terkonfirmasinya beberapa bahasa daerah di Maluku yang dinyatakan punah. Kepunahan bahasa daerah di Maluku berimbas pada punahnya sastra daerah termasuk cerita rakyat. Atas dasar itulah kemudian digalakan upaya pelestarian sastra daerah-salah satunya cerita rakyat-dengan cara didokumentasikan, dibukukan, dikembangkan, dan sampai didigitalisasikan sehingga bisa diakses oleh khalayak umum. Tidak berhenti sampai di sini, berbagai jenis kajian pun dilakukan oleh para akademisi, pengkaji, dan peneliti. Beberapa kajian cerita rakyat Maluku yang pernah dilakukan, antara lain: (1) Analisis Nilai Budaya dalam Cerita Rakyat Maluku Air Tukang oleh Helmina Kastanya tahun 2020; (2) Motif dan Tipe dalam Cerita Rakyat Kepulauan Aru oleh Nita Handayani Hasan tahun 2017; (3) Penerapan Teori Vladimir Propp pada Cerita Rakyat Ikan Lompa oleh Nita Handayani Hasan tahun 2016; dan (4) 
Cerita Rakyat Jaka Tarub dan Air Tukang: Suatu Kajian Sastra Bandingan oleh Nita Handayani Hasan tahun 2016. Adapun penulis dalam hal ini akan membahas nilai moral dalam tokoh cerita Buaya Learisa Kayeli. Alasan pemilihan cerita rakyat ini karena (1) belum pernah dikaji melalui kajian sastra anak; (2) para tokoh penting diperankan oleh karakter binatang sehingga nilai fantasinya lebih tinggi daripada cerita dengan tokoh manusia; (3) cerita ini diperuntukkan bagi anak-anak terutama kelas 4, 5, dan 6; (4) memiliki cerita yang utuh; dan (5) merupakan cerita rakyat Maluku yang sudah dibukukan dan sudah berbahasa Indonesia bahkan sudah mengalami proses digitalisasi.

Berbicara tentang sastra anak, maka perlu sebuah pemahaman yang sama terkait kategorisasi anak itu sendiri. Anak yang dimaksud bukanlah anak yang biasa disebut dengan anak Kober, anak TK, anak SD, anak SMP, anak SMA, dan anak kuliahan. Akan tetapi, anak yang menjadi target sasaran sastra anak adalah anak yang berusia 0 sampai dengan 12 tahun (Ampera, 2010:14-15). Genre sastra anak yang diberikan kepada anak disesuaikan dengan usianya. Misalnya, nyanyian Keplok Ame-Ame, Belalang Кири-Кири termasuk genre sastra anak yang hanya bisa diterima oleh anak berusia 0-2 tahun dan begitu seterusnya berlaku untuk genre satra anak lainnya.

Berdasarkan uraian di atas, maka rumusan masalah yang akan dibahas dalam kajian ini adalah (1) tentang tokoh cerita Buaya Learisa Kayeli dan (2) nilai moral yang terdapat dalam tokoh cerita tersebut. Kajian ini bertujuan untuk menentukan tokoh-tokoh dalam cerita Buaya Learisa Kayeli dan menafsirkan nilai moral yang disampaikan oleh pengarang melalui tokoh-tokoh cerita tersebut. Adapun hasil dari kajian ini diharapkan bisa memberikan informasi kepada khalayak umum bahwa edukasi moral berbasis sastra anak bisa melalui cerita rakyat.

\section{LANDASAN TEORI}

Aspek sastra anak merujuk pada gagasan Nurgiyantoro (2019:104-108) yang terdiri dari alur, penokohan, tema dan moral, latar, stile, ilustrasi, dan format. Nilai moral yang disampaikan pengarang dalam cerita rakyat Maluku berjudul Buaya Learisa Kayeli bisa dieksplorasi melalui aspek penokohan. Nurgiyantoro (2019:111) membagi aspek penokohan ke dalam tokoh dan perwatakan tokoh. Dalam bacaan anak, tokoh dapat berupa manusia, binatang, peri, hantu, dan tumbuhan, bahkan tokoh gabungan seperti manusia dan binatang dapat berjalan bersama menjadi tokoh cerita.

Pada umumnya, cerita anak menampilkan tokoh yang terbelah, yaitu tokoh berkualifikasi baik dan jahat, tokoh putih dan hitam, dan jarang ada tokoh berkualifikasi "abu-abu" (Nurgiyantoro, 2019:113). Maksudnya, watak tokoh dalam cerita anak itu sama, tidak berubah dari awal sampai akhir cerita, yang baik selamanya tetap baik, yang jahat selamanya tetap jahat. Pengungkapan watak tokoh dilakukan dengan cara uraian atau dramatik. Pengungkapan watak dengan cara dramatik tampaknya kurang efektif untuk anak usia prasekolah dan sekolah kelas rendah, tetapi sudah dapat diterima oleh anak-anak kelas yang lebih tinggi, tetapi derajat kedramatikannya tentunya masih tergolong sederhana (Nurgiyantoro, 2019:115). Maka dari itu, pengungkapan watak tokoh dalam cerita anak kelas tinggi (kelas 4, 5, dan 6 sekolah dasar) bisa dilakukan dengan cara uraian maupun dramatik, dengan catatan, cara uraian lebih dominan dari cara dramatik.

Menurut KBBI (2016), watak adalah sifat batin manusia yang memengaruhi segenap pikiran dan tingkah laku, sedangkan karakter adalah sifat-sifat kejiwaan, akhlak atau budi pekerti yang membedakan seseorang dari yang lain. Dari kedua pengertian tersebut disa 
disimpulkan bahwa watak adalah karakter itu sendiri. Maka dari itu, untuk memudahkan penulis dalam mendeskripsikan watak baik pada tokoh dalam cerita Buaya Learisa Kayeli, penulis akan merujuk pada nilai karakter yang digaungkan oleh pemerintah Republik Indonesia (2010:22) bahwa karakter individu yang dijiwai oleh sila-sila Pancasila dapat dikemukakan sebagai berikut.

1) Karakter yang bersumber dari olah hati, antara lain: beriman dan bertakwa (religius), jujur, amanah, adil, tertib, taat aturan, bertanggung jawab, berempati, berani mengambil resiko, pantang menyerah, rela berkorban, dan berjiwa patriotik;

2) Karakter yang bersumber dari olah pikir, antara lain: cerdas, kritis, kreatif, inovatif, ingin tahu, produktif, berorientasi ipteks, dan reflektif;

3) Karakter yang bersumber dari olah raga, antara lain: bersih, sehat, sportif, tangguh, andal, berdaya tahan, bersahabat, kooperatif, determinatif, kompetitif, ceria, dan gigih; dan

4) Karakter yang bersumber dari olah rasa dan karsa, antara lain: kemanusiaan, saling menghargai, gotong royong, kebersamaan, ramah, hormat, toleran, nasionalis, peduli, kosmopolit (mendunia), mengutamakan kepentingan umum, cinta tanah air (patriotis), bangga menggunakan bahasa dan produk Indonesia, dinamis, kerja keras, dan beretos kerja.

Nilai moral juga memiliki pengertian yang berbeda-beda. Para ahli mengartikan nilai dan moral sesuai sudut pandang dan kebutuhannya masingmasing. Mengutip pendapat dari Zakiyah dan Rusdiana, nilai adalah segala hal yang berhubungan dengan tingkah laku manusia mengenai baik atau buruk yang diukur oleh agama, tradisi, etika, moral, dan kebudayaan yang berlaku dalam masyarakat (2014:15) sedangkan moral berhubungan dengan perasaan salah atau benar terhadap kebahagiaan orang lain atau perasaan terhadap tindakan yang dilakukan diri sendiri (2014:178). Dari pendapat tersebut dapat disimpulkan bahwa nilai moral adalah suatu ajaran baik-buruk atau benar-salah menurut kacamata agama, tradisi, etika, dan kebudayaan dalam masyarakat yang akan berdampak pada perangai manusia dan kebahagiaan orang lain. Nilai moral dalam tokoh cerita rakyat berarti ajaran yang disampaikan oleh pengarang melalui tokoh-tokoh yang ada dalam cerita rakyat baik secara tersurat maupun tersirat.

\section{METODE}

Karya sastra perlu ditafsirkan sebab karya sastra terdiri atas bahasa dan di dalam bahasa sangat banyak makna yang tersembunyi atau dengan sengaja disembunyikan (Ratna, 2013:45). Perlu adanya alat dan cara untuk menafsirkan makna suatu bahasa yang terkandung dalam karya sastra. Alat itu yang kemudian disebut dengan teori dan cara itu yang kemudian disebut dengan metode. Metode adalah cara yang teratur yang digunakan untuk melaksanakan suatu pekerjaan agar tercapai hasil yang baik seperti yang dikehendaki (Badudu dan Sutan, 1994:896).

Kaitannya dengan cerita Buaya Learisa Kayeli sebagai sumber data, maka jenis kajian ini adalah kualitatif dengan menggunakan metode deskriptif analisis isi. Metode dalam kajian ini menggabungkan dua metode, yaitu metode deskriptif dan analisis isi. Metode deskriptif dilakukan dengan cara mendeskripsikan fakta-fakta (Ratna, 2013:53) sedangkan analisis isi dilakukan dengan cara menafsirkan isi pesan (Ratna, 2013:49). Jadi, metode deskriptif analisis isi adalah metode yang dilakukan dengan cara mendeskripsikan fakta-fakta yang kemudian disusul dengan penafsiran isi 
pesan.

Kajian ini menggunakan pendekatan sastra anak. Adapun teknik pengumpulan data yang digunakan adalah studi kepustakaan dengan cara melakukan pembacaan cerita, pembuatan sinopsis, penentuan tokoh, dan pendeskripsian watak tokoh. Dalam pendeskripsian watak tokoh yang berkualifikasi baik akan merujuk pada nilai karakter yang diusung oleh pemerintah Republik Indonesia seperti uraian di atas, sedangkan untuk watak tokoh yang berkualifikasi jahat akan dideskripsikan apa adanya sesuai fakta. Setelah itu, teknik analisis data dilakukan untuk menafsirkan nilai moral yang terkandung dalam tokoh cerita.

\section{PEMBAHASAN}

Buaya Learisa Kayeli merupakan salah satu judul buku cerita rakyat Maluku yang ditulis dan dikembangkan oleh Asrif. Buku ini diterbitkan oleh Badan Pengembangan dan Pembinaan Bahasa Kemendikbud tahun 2016. Buku cerita ini dikategorikan sebagai bahan bacaan untuk anak kelas 4, 5, dan 6 sekolah dasar ataupenulis menyebutnya-kelas tinggi. Cerita rakyat ini digolongkan ke dalam cerita binatang karena para tokoh penting diperankan oleh binatang. Interaksi antara binatang dengan manusia yang terjadi dalam cerita ini hanyalah sebagai pendukung cerita saja. Cerita Buaya Learisa Kayeli juga bisa digolongkan ke dalam legenda karena pada bagian pertengahan sampai akhir cerita ini dikisahkan asal-usul ikan lompa, ikan make, dan ikan parang-parang yang ada di perairan Maluku. Akan tetapi, asal-usul ikan tersebut tidak menjadi dominan dalam cerita rakyat ini.

\section{Sinopsis Buaya Learisa Kayeli}

Cerita Buaya Learisa Kayeli mengisahkan seekor buaya betina yang hidup di Sungai Learisa Kayeli, Negeri Aman Harukui, Pulau Haruku. Buaya itu dijuluki Raja Sungai Learisa Kayeli karena suka menolong warga dengan cara membiarkan punggungnya menjadi tempat pijakan warga yang hendak menyeberangi sungai pada saat air sungai meluap. Raja Sungai Learisa Kayeli adalah satu-satunya buaya yang hidup di sungai tersebut. Ia menjadi penjaga sekaligus penguasa tunggal di sepanjang sungai.

Pada suatu hari, ada sekelompok Buaya Pulau Seram datang menemui Raja Learisa Kayeli. Mereka hendak meminta bantuan Raja untuk mengalahkan Ular Raksasa yang mengusik kehidupan mereka. Ular Raksasa itu telah menyerang buaya-buaya Pulau Seram sampai beberapa di antaranya ada yang tewas dan luka-luka. Meski Sang Raja sedang hamil tua, tapi ia tidak tega membiarkan saudara-saudaranya di pulau seberang hidup tertindas di bawah kekuasaan Ular Raksasa. Setelah beberapa saat berpikir, dengan segenap keteguhan hati, Sang Raja memutuskan akan membantu buaya-buaya Pulau Seram.

Setelah berhari-hari Sang Raja dan sekelompok Buaya Pulau Seram berenang menembus ombak dan menerjang badai, akhirnya mereka tiba di Tanjung Sial, Pulau Seram. Pada saat yang bersamaan, Ular Raksasa yang sedang bergelantungan di pohon melihat kedatangan mereka. Tidak lama kemudian, pertarungan pun terjadi antara Raja Learisa Kayeli dan Ular Raksasa. Setelah sekian lama saling menyerang, Raja Learisa Kayeli tampak terluka akibat gigitan dan lilitan ular. Ular Raksasa yang merasa akan memenangi pertarungan pun menjadi congkak. Pada saat itulah, Raja Learisa Kayeli melihat kesempatan untuk menyerang. Dengan sekuat tenaga, ekor Sang Raja dihentakkan ke tubuh Ular Raksasa. Sang Raja menyerang berkali-kali sehingga membuat Ular Raksasa sekarat dan akhirnya tewas.

Setelah memenangkan pertarungan, Raja Learisa Kayeli melakukan perjalanan pulang ke Pulau Haruku. Sebagai tanda terima kasih, Sang Raja mendapat hadiah 
dari buaya-buaya Pulau Seram berupa ikan lompa, ikan make, dan ikan parang-parang. Di pertengahan jalan pulang, tepatnya di Pantai Waai, tubuh Sang Raja melemah sehingga tidak bisa melanjutkan perjalanan. Di sanalah kemudian Sang Raja melahirkan anaknya sebelum akhirnya ia tewas.

Sepeninggal Raja Learisa Kayeli, Buaya Muda - anak Sang Raja-belajar berenang di Pantai Waai. Setelah merasa mantap, Buaya Muda melakukan perjalanan menuju Pulau Haruku untuk meneruskan kebajikan ibunya. Ia tak lupa turut serta membawa semua ikan pemberian buaya-buaya Pulau Seram. Buaya Muda sempat tersesat di Pantai Passo sebelum akhirnya tiba di tempat tujuan, yaitu Sungai Learisa Kayeli, Negeri Aman Harukui, Pulau Haruku. Nahasnya, ikan parang-parang tertinggal di pantai Passo saat ia tersesat. Hanya ikan lompa dan ikan make yang berhasil tiba di tempat tujuan bersama Buaya Muda.

\section{Eksplorasi Nilai Moral \\ 1 Penentuan Tokoh}

Ada enam tokoh yang ditemukan dalam cerita Buaya Learisa Kayeli, antara lain: Buaya Learisa Kayeli, Buaya Pulau Seram, Ular Raksasa, Buaya Muda, Tiga Jenis Ikan, dan Manusia.

\section{Perwatakan Tokoh}

Berikut ini adalah penjelasan watak para tokoh mulai dari tokoh dengan intensitas kepentingan - dalam ceritapaling tinggi sampai paling rendah. Intensitas kepentingan tokoh dilihat dari keseringannya muncul dalam cerita.

\subsection{Buaya Learisa Kayeli}

Buaya Learisa Kayeli yang peduli terhadap makhluk lain diungkapkan dengan cara uraian ketika warga hendak menyeberangi sungai dan dramatik ketika datang sekelompok Buaya Pulau Seram untuk meminta bantuan.

\begin{abstract}
'Walau tampak menyeramkan, Buaya Sungai Learisa Kayeli tidak pernah menyerang warga sekitar sungai. Malah sebaliknya, Sang Buaya suka menolong warga yang hendak menyeberangi sungai (Asrif, 2016:3).'

"Saya akan membantu kalian, saudarasaudaraku dari Pulau Seram," jawab Sang Raja Sungai Learisa Kayeli (Asrif, 2016:13).'
\end{abstract}

Buaya Learisa Kayeli yang kosmopolit diungkapkan dengan cara uraian selama tinggal di Pulau Haruku dan cara dramatik oleh Buaya Pulau Seram.

'Perilaku Sang Buaya yang suka menolong
terkenal ke seantero Negeri Aman Harukui
(Asrif, 2016:4).'
'“Kita ke Pulau Haruku untuk meminta
bantuan Raja Sungai Learisa Kayeli," ucap
salah satu dari kawanan buaya itu (Asrif,
2016:9-10).'
Buaya Learisa Kayeli yang berani mengambil resiko, berempati, dan peduli diungkapkan secara uraian dan ditegaskan dengan cara dramatik ketika ia memutuskan untuk membantu sekelompok Buaya Pulau Seram meski pada saat itu ia tengah hamil tua.

'Pada saat kawanan Buaya Pulau Seram datang, Buaya Learisa Kayeli sedang hamil tua. ... Akan tetapi, Buaya Learisa Kayeli tidak tega melihat dan mendengar saudara-saudaranya dari Pulau Seram telah sekarat dan beberapa di antaranya tewas dibunuh Ular Raksasa.

"Saya akan membantu kalian, saudarasaudaraku dari Pulau Seram," jawab Sang Raja Sungai Learisa Kayeli (Asrif, 2016:12-13).'

Buaya Learisa Kayeli yang gigih diungkapkan secara uraian dalam perjalanan menuju Pulau Seram.

'Bersama dengan kawanan Buaya Pulau Seram, Raja Learisa Kayeli berangkat menuju Tanjung Sial. Berhari-hari mereka berenang menembus ombak dan menerjang badai hingga kemudian mereka tiba di Tanjung Sial (Asrif, 2016:15).' 
Buaya Learisa Kayeli yang berjiwa kompetitif diungkapkan secara uraian ketika bertemu dengan Ular Raksasa.

'Melihat gerak-gerik Ular Raksasa yang hendak menyerang, Raja Learisa Kayeli tidak gentar. Sang Raja terus berenang. Ia mendekati pohon tempat Ular Raksasa berada (Asrif, 2016:16).'

Buaya Learisa Kayeli yang berdaya tahan diungkapkan secara uraian saat melakukan perlawanan terhadap Ular Raksasa.

'Namun, Raja Learisa Kayeli tidak akan menyerah begitu saja. Walau masih lelah setelah melakukan perjalanan panjang dari Pulau Haruku ke Pulau Seram, Raja Learisa Kayeli melakukan perlawanan sengit terhadap Ular Raksasa (Asrif, 2016:16-17).'

Buaya Learisa Kayeli yang dapat diandalkan sebagai bentuk rasa tanggung jawabnya dalam membela sekelompok buaya Pualau Seram yang terusik oleh Ular Raksasa diungkapkan dengan uraian.

'Ia tidak ingin mengecewakan kaumnya. Ia tidak ingin semua buaya takluk di tangan Ular Raksasa pengganggu kedamaian Buaya Pulau Seram. Sang Raja Learisa Kayeli berjuang sekuat tenaga untuk mengalahkan Ular Raksasa (Asrif, 2016:17).'

Buaya Learisa Kayeli yang cerdas dan reflektif diungkapkan secara uraian ketika berhadapan dengan Ular Raksasa.

'Sang Raja Learisa Kayeli tidak ingin gegabah menghadapi serangan dan gertakan lawan. Ia selalu waspada dan berusaha menghindari serang mematikan dari Ular Raksasa (Asrif, 2016:18).'

Buaya Learisa Kayeli yang pantang menyerah diungkapkan secara uraian di akhir pertarungan.
'Dengan sekuat tenaga, ekor Raja Learisa Kayeli yang panjang dihentakkan ke tubuh Ular Raksasa. Raja Learisa Kayeli menyerang berkali-kali. Ular Raksasa sekarat dan akhirnya tewas (Asrif, 2016:19).'

Buaya Learisa Kayeli yang tegar sebagai bentuk ketangguhannya setelah memenangkan pertempuran diungkapkan dengan cara uraian dan ditegaskan dengan cara dramatik.

\footnotetext{
'Walau begitu, Buaya Learisa Kayeli tetap memperlihatkan ketegarannya. Ia tidak mau buaya-buaya Pulau Seram bersedih hati melihat kondisi fisiknya yang melemah. Ia harus tetap tampak kuat di hadapan buaya-buaya Pulau Seram. Ia harus tegar.

"Saya baik-baik saja," ucap Raja Learisa Kayeli kepada buaya-buaya Pulau Seram (Asrif, 2016:22).'
}

Buaya Learisa Kayeli yang cinta tanah air diungkapkan dengan cara dramatik dan uraian setelah memenangkan pertarungan.

\footnotetext{
"'Saya harus segera kembali ke Pulau Haruku. Saya sudah lama meninggalkan Sungai Learisa Kayeli,” lanjut Sang Raja.

Buaya-buaya Pulau Seram ingin agar Raja Learisa Kayeli menetap bersama meraka di Tanjung Sial. Akan tetapi, hal tersebut tidaklah mungkin terwujud karena Raja Learisa Kayeli tetap ingin kembali hidup di negerinya yang indah dan damai, Sungai Learisa Kayeli di Negeri Aman Harukui, Pulau Haruku (Asrif, 2016:24).'
}

\section{Buaya Learisa Kayeli yang tanpa pamrih sebagai wujud sikap mengutamakan kepentingan umum di atas kepentingan pribadi diungkapkan dengan uraian pascapertarungan dan secara dramatik saat diberi hadiah tiga jenis ikan oleh Buaya Pulau Seram.}

'Sang Raja yang sedag terluka tidak mengeluh dan meminta belas-kasih atas jasanya mengalahkan Ular Raksasa. Itulah jiwa pemimpin sejati. Pemimpin itu selalu bekerja tanpa mengharapkan imbalan 
apapun dari pihak yang ditolongnya (Asrif, 2016:25).'

“"Ambillah ikan-ikan ini untuk makanan buaya-buaya yang ada di sini. Kalian amat membutuhkan makanan setelah sekian lama terusik oleh kehadiran Ular Raksasa," lanjut Sang Raja dengan bijaknya (Asrif, 2016:27).'

Buaya Learisa Kayeli yang rela berkorban bahkan nyawa sekali pun diungkapkan dengan cara uraian dalam perjalanan pulang menuju Pulau Haruku.

'Sang Raja yang terkenal suka menolong itu meninggal dalam perjalanan pulang dari Pulau Seram. Sang Raja meninggal karena luka-luka bekas gigitan dan lilitan Ular Raksasa di Tanjung Sial (Asrif, 2016:22).'

\subsection{Buaya Pulau Seram}

$\begin{array}{cccc}\text { Buaya } & \text { Pulau } & \text { Seram yang } \\ \text { mengutamakan } & \text { gotong } & \text { royong } & \text { dan }\end{array}$ kebersamaan diungkapkan dengan cara uraian dalam menjalani kehidupan seharihari di Pulau Seram.

'Pada bagian barat Pulau Seram, beberapa ekor buaya hidup rukun dan damai. Mereka mencari makan bersama-sama, saling berbagi, saling menolong, dan saling melindungi (Asrif, 2016:6).'

Buaya Pulau Seram yang cinta tanah air diungkapkan dengan cara dramatik saat Ular Raksasa datang mengusik.

“"Kami tidak takut! Kami akan mempertahankan kawasan ini. Tak semudah itu kami akan pergi dari sini," jawab Buaya Pulau Seram (Asrif, 2016:7).'

Buaya Pulau Seram yang saling menghargai pendapat orang lain tercermin dalam musyawarah-mufakat yang dilakukan dengan cara dramatik lalu ditegaskan dengan uraian.

\begin{abstract}
" "Kita harus mencari bantuan ke negeri lain," teriak salah satu buaya yang tampak kepayahan melawan Ular Raksasa.

"Baiklah. Ular Raksasa ini sangat kuat. Ia menyerang kita dengan ganas. Saudarasaudara kita telah banyak yang tewas. Kita harus segera pergi mencari bantuan," kata pimpinan Buaya Pulau Seram.

"Kita ke Pulau Haruku untuk meminta bantuan Raja Sungai Learisa Kayeli," ucap salah satu dari kawanan buaya itu.

Akhirnya, mereka bersepakat untuk meminta bantuan Raja Sungai Learisa Kayeli (Asrif, 2016:9-10).'
\end{abstract}

Buaya Pulau Seram yang religius diungkapkan secara uraian saat menyaksikan pertarungan antara Sang Raja dan Ular Raksasa.

'Kawanan Buaya Pulau Seram sangat waswas. Mereka berdoa agar Raja Learisa Kayeli diberi kekuatan untuk mengalahkan Ular Raksasa (Asrif, 2016:18).'

Buaya Pulau Seram yang sangat menghormati sosok Raja Learisa Kayeli atas keberhasilannya mengalahkan Ular Raksasa diungkapkan secara dramatik dan ditegaskan dengan uraian.

“"Hidup Raja Learisa Kayeli! Hidup Raja Learisa Kayeli!" teriak buaya-buaya Pulau Seram (Asrif, 2016:20).'

'Mendengar jawaban Sang Raja, buayabuaya Pulau Seram sangat terharu. Mereka makin mengagumi sosok Raja Learisa Kayeli yang arif dan bijaksana itu (Asrif, 2016:25).'

Buaya Pulau Seram yang berempati ketika Sang Raja hendak kembali ke Pulau Haruku pascapertarungan diungkapkan dengan cara uraian.

'Mendengar ucapan Raja Learisa Kayeli, kawanan Buaya Pulau Seram bersedih hati. Mereka tidak tahu dengan apa harus membalas kebaikan Raja Learisa Kayeli. Sang Raja menjadi terluka dan kelelahan karena telah membantu mereka menaklukkan Ular Raksasa (Asrif, 2016:23).’ 
Buaya Pulau Seram yang peduli ketika Sang Raja hendak kembali ke Pulau Haruku pascapertarungan diungkapkan dengan cara dramatik.

“"Wahai Sang Raja, beristirahatlah di sini selama beberapa hari. Raja perlu istirahat untuk mengembalikan tenaga. Juga, lukaluka Raja Learisa Kayeli perlu dirawat," pinta Buaya Pulau Seram (Asrif, 2016:23).'

Buaya Pulau Seram yang tau balas budi sebagai bentuk upaya saling menghargai diungkapkan dalam uraian ketika Raja Learisa Kayeli hendak kembali ke Pulau Haruku.

'Sebelum meninggalkan Tanjung Sial, Raja Learisa Kayeli diberi bekal oleh buaya-buaya Pulau Seram. Bekal tersebut berupa tiga jenis ikan, yang banyak hidup di perairan Tanjung Sial. Ikan-ikan itu yakni ikan lompa, ikan make, dan ikan parang-parang (Asrif, 2016:26).'

Buaya Pulau Seram yang bersahabat diungkapkan secara dramatik saat memberikan hadiah untuk Sang Raja dan ditegaskan melalui uraian saat hadiah itu diterima oleh Sang Raja.

"“Ikan-ikan ini tidak hanya untuk menjadi makanan selama dalam perjalanan, tetapi juga akan menjadi bukti hubungan baik antara kami di Tanjung Sial dan Raja di Sungai Learisa Kayeli," lanjut Buaya Pulau Seram itu (Asrif, 2016:28).'

'Mereka bergembira karena ikan yang mereka berikan akhirnya diterima oleh Raja Learisa Kayeli. Ikan itu dapat menjadi penanda ikatan persaudaraan antarmereka (Asrif, 2016:28-29).'

\subsection{Ular Raksasa}

Ular Raksasa sebagai pengusik kedamaian hewan lain diungkapkan dengan cara uraian dan dramatik dalam kedatangannya di Pulau Haruku.

'Namun, pada suatu hari kedamaian sekelompok buaya itu terusik oleh kehadiran seekor ular berbadan besar dan panjang. Ular itu adalah Ular Raksasa.

"Pergilah kalian dari kawasan ini," perintah Ular Raksasa. "Sekarang kawasan ini menjadi kekuasaan saya," lanjutnya (Asrif, 2016:6).'

Ular Raksasa yang sombong diungkapkan dengan cara dramatik dan uraian saat bertarung dengan Raja Learisa Kayeli.

\footnotetext{
“"Saya akan mengalahkanmu seperti halnya buaya-buaya Pulau Seram," teriak Ular Raksasa dengan pongahnya. "Kamu akan bernasib sama dengan buaya-buaya Pulau Seram," lanjutnya (Asrif, 2016:17).' 'Ular Raksasa yang merasa akan memenangi pertempuran itu menjadi congkak. Saat Ular Raksasa bersikap congkak, Raja Learisa Kayeli melihat kesempatan untuk menyerang. Dengan sekuat tenaga, ekor Raja Learisa Kayeli yang panjang dihentakkan ke tubuh Ular Raksasa. Raja Learisa Kayeli menyerang berkali-kali. Ular Raksasa sekarat dan akhirnya tewas (Asrif, 2016:18-19).'
}

\subsection{Buaya Muda}

Buaya Muda yang berdaya tahan tercermin dari kemandiriannya dalam mempertahankan hidup tanpa orang tua. Hal ini diungkapkan melalui uraian berikut.

\footnotetext{
'Selain belajar berenang, Buaya Muda itu juga belajar cara mencari makanan. Ia harus belajar mempertahankan hidup tanpa bantuan orang lain. Ia harus kuat dan mandiri karena ia hidup sebatang kara. Buaya Muda tidak boleh bersikap lemah. Ia harus menjadi Buaya Muda yang kuat, tagguh, dan bijaksana (Asrif, 2016:35).'
}

Buaya Muda yang determinatif dalam menentukan kelanjutan hidupnya diungkapkan melalui uraian setelah ia pandai berenang dan mencari makan sendiri.

'Dengan berat hati, Buaya Muda melanjutkan perjalanan ibunya untuk menuju Sungai Learisa Kayeli, tempat ibunya tumbuh dan berkembang. Buaya 
Muda bertekad untuk menjaga Sungai Learisa Kayeli dan menolong warga setempat (Asrif, 2016:36).'

$\begin{array}{lccc}\begin{array}{c}\text { Buaya } \\ \text { Muda yang }\end{array} & \text { berani } \\ \text { diungkapkan melalui uraian } & \text { dalam } \\ \text { perjalanan menuju Pulau Haruku. } & \end{array}$

'Sang Buaya Muda aktif menggerakkan kaki dan mengibaskan ekor. Ia berenang menuju Pulau Haruku. Ia telah berani melintasi lautan bebas, menerjang ombak dan derasnya arus laut (Asrif, 2016:37).'

Buaya Muda memiliki rasa ingin tahu yang tinggi. Hal ini diungkapkan melalui uraian ketika tersesat di Pantai Passo.

'Buaya Muda berusaha sekuat tenaga untuk menemukan jalan menuju Pulau Haruku. Ia tidak mengajak serta ikan lompa, ikan make, dan ikan parang-parang untuk mencari informasi tentang arah jalan ke Pulau Haruku. Ketiga ikan itu dibiarkannya bermain di perairan Pantai Passo (Asrif, 2016:38).'

Buaya Muda yang pantang menyerah diungkapkan melalui uraian pada saat mencari informasi jalan menuju Pulau Haruku.

'Anak Raja Learisa Kayeli itu bertanya kepada siapa saja yang ditemuinya. Ia berenang ke utara, ke selatan, ke timur, dan ke barat. Setiap orang yang ditemui di jalan, ia akan menanyakan arah jalan menuju Pulau Haruku. Buaya Muda tidak lelah untuk bertanya hingga kemudian ia memperoleh petunjuk tentang arah jalan menuju Pulau Haruku. Ia gembira usahanya berhasil (Asrif, 2016:38).'

Buaya Muda yang kritis diungkapkan melalui uraian ketika ia memutuskan untuk berhenti di tengah perjalanan dari Pantai Passo menuju Pulau Haruku karena ada perasaan mengganjal dalam hatinya.

'Buaya Muda memperhatikan daerah sekelilingnya. Matanya tajam mengamati setiap benda atau apa saja yang ada di sekitarnya. Ikan-ikan yang turut menyertai perjalanannya menuju Pulau Haruku juga tak luput dari perhatiannya (Asrif, 2016:39).'

Buaya Muda yang peduli kepada pengikutnya diungkapkan secara dramatik dan uraian ketika ia menyadari bahwa ikan parang-parang tidak turut serta dalam rombongan.

\footnotetext{
““Astaga!” teriak Buaya Muda.

"Mana ikan parang-parang?"

"Ikan parang-parang!"

Buaya Muda terus memanggil-manggil ikan parang-parang agar segera bergabung dengan dirinya. Buaya Muda menyelam ke kedalaman laut siapa tahu ikan parangparang berada di bagian laut dalam (Asrif, 2016:40).'
}

Buaya Muda yang menghayati kuatnya rasa kebersamaan diungkapkan melalui uraian ketika ia menyadari bahwa ikan parang-parang tidak turut serta dalam rombongan karena tertinggal di Pantai Passo.

'Ada perasaan haru di hati Buaya Muda. Ia tak henti mengenang ikan parang-parang yang sekian lama setia bersamanya. Bahkan, sebelum bersama dirinya, ikan parang-parang telah lama bersama ibunya, Raja Learisa Kayeli (Asrif, 2016:42).'

Buaya Muda yang gigih diungkapkan melalui uraian setelah ia memutuskan untuk melanjutkan perjalanan ke Pulau Haruku tanpa ikan parang-parang.

'Mereka menerjang ombak, menghadang badai, dan arus laut antara Pulau Ambon dan Pulau Haruku. Terik matahari tidak menjadi penghalang semangat mereka. Buaya Muda, ikan lompa, dan ikan make berenang menuju Pulau Haruku (Asrif, 2016:42-43).'

Buaya Muda yang ramah diungkapkan dengan cara uraian ketika sudah sampai di Pulau Haruku.

'Buaya Muda menyapa siapa pun orang yang berada di sekitar Sungai Learisa Kayeli. Ia berenang perlahan-lahan seakan ingin mengukur setiap inci bagian aliran 
Sungai Learisa Kayeli (Asrif, 2016:45).'

Buaya Muda yang bertanggung jawab diungkapkan melalui uraian selama berada di Pulau Haruku.

'Di Sungai Learisa Kayeli, buaya kecil hidup Bersama ikan-ikan pemberian buaya-buaya Pulau Seram. Buaya Muda menjaga dengan baikikan lompa dan ikan make dari gangguan makhluk lain (Asrif, 2016:45).'

Buaya Muda yang tangguh diungkapkan melalui uraian ketika ia beranjak dewasa.

'Beberapa tahun kemudian, buaya kecil tumbuh menjadi buaya dewasa yang tangguh. Ia memiliki badan yang kekar, ekor yang bertenaga, dan gigi yang tajam (Asrif, 2016:46).'

Buaya Muda yang bersahabat diungkapkan dengan cara uraian ketika ia dewasa dan melanjutkan teladan baik dari ibunya.

'Seperti ibunya, anak Raja Learisa Kayeli itu rajin menolong warga yang hendak menyeberangi sungai. Jadi, anak Raja Learisa Kayeli itu pun akrab dengan warga (Asrif, 2016:46).'

Buaya Muda yang kooperatif dengan warga diungkapkan melalui uraian di bagian akhir cerita ini.

'Limpahan ikan tersebut tidak hanya dinikmati oleh buaya seorang diri, tetapi juga oleh warga lain. Buaya menjaga waga dan warga juga menjaga buaya. Keduanya saling menjaga agar tercipta kehidupan yang damai dan sejahtera (Asrif, 2016:47).'

\subsection{Tiga Jenis Ikan}

Ikan lompa, ikan make, dan ikan parang-parang yang amanah tercermin dalam kesetiaan mereka terhadap Sang Raja dan Buaya Muda dalam perjalanan menuju Pulau Haruku. Hal ini diungkapkan dengan cara uraian.

\begin{abstract}
'Bersama-sama dengan ikan lompa, ikan make, dan ikan parang-parang (yang) setia, Sang Raja berenang menembus derasnya arus laut. ... Sang Raja terus berenang menuju Pulau Haruku (Asrif, 2016:31).'

'Ikan lompa, ikan make, dan ikan parangparang mengiringi perjalanan Buaya Muda. Mereka berenang bersama-sama dan tampak sebagai satu rombongan besar. Ikan-ikan itu hendak dibawanya ke Sungai Learisa Kayeli di Pulau Haruku (Asrif, 2016:36).'
\end{abstract}

Ikan lompa, ikan make, dan ikan parang-parang yang dapat diandalkan diungkapkan melalui uraian saat mereka berkembang biak dengan jumlah yang melimpah.

'Karena jumlahnya yang semakin melimpah, ikan lompa dan ikan make menjadi ikan andalan masyarakat Pulau Haruku. Demikian pula halnya ikan parang-parang yang menjadi ikan yang paling banyak dijumpai di perairan Passo (Asrif, 2016:46).'

\subsection{Manusia}

Warga Pulau Haruku yang peduli lingkungan sekitar diungkapkan dengan cara uraian.

'Selain tanah yang subur, Pulau Haruku juga memiliki sungai yang jernih airnya. Warga sekitar menjaga sungai agar tidak tercemar sampah. Ikan-ikan bertelur dan berkembang biak dengan baik (Asrif, 2016:1).'

Warga Pulau Haruku yang tau balas budi sebagai bentuk upaya saling menghargai diungkapkan secara uraian.

'Warga menyematkan cincin ke jari Sang Buaya sebagai tanda terima kasih atas kebaikan Sang Buaya. Seperti itulah cara warga Negeri Aman Harukui menjaga hubungan baik dengan Sang Buaya (Asrif, 2016:5).'

Warga Waai yang berempati diungkapkan melalui uraian saat Sang Raja 
terdampar di Pantai Waai karena kelelahan.

'Pada saat warga Waai menuju pantai, terkejutlah mereka melihat seekor buaya besar yang sedang sekarat. Buaya itu adalah Raja Learisa Kayeli. Mereka sangat iba melihat buaya itu. Akan tetapi, mereka tidak tahu harus dengan cara apa menolong Sang Buaya (Asrif, 2016:34).’

Warga setempat yang adil memanfaatkan kekayaan alam di sekitarnya diungkapkan melalui uraian berikut.

\begin{abstract}
'Walau ikan-ikan tersebut melimpah, warga setempat memanfaatkannya sesuai dengan kebutuhan mereka. Hal ini dilakukan untuk menjaga keberlanjutan ikan-ikan tersebut di perairan Pulau Haruku dan Pantai Passo (Asrif, 2016:47).'
\end{abstract}

\section{Nilai Moral}

Berdasarkan uraian di atas, maka nilai moral yang disampaikan pengarang dalam tokoh cerita Buaya Learisa Kayeli adalah sebagai berikut.

\subsection{Buaya Learisa Kayeli}

Rangkuman perwatakan tokoh Buaya Learisa Kayeli, antara lain: 1) peduli terhadap yang lain ketika warga hendak menyeberangi sungai dan ketika datang sekelompok Buaya Pulau Seram untuk meminta bantuan, 2) kosmopolit selama tinggal di Pulau Haruku dan dikenal oleh Buaya Pulau Seram, 3) berani mengambil resiko, berempati, dan peduli ketika ia memutuskan untuk membantu sekelompok Buaya Pulau Seram meski pada saat itu ia tengah hamil tua, 4) gigih dalam perjalanan menuju Pulau Seram, 5) berjiwa kompetitif ketika bertemu dengan Ular Raksasa, 6) berdaya tahan saat melakukan perlawanan terhadap Ular Raksasa, 7) dapat diandalkan sebagai bentuk rasa tanggung jawabnya dalam membela sekelompok buaya Pualau Seram yang terusik oleh Ular Raksasa, 8) cerdas dan reflektif ketika berhadapan dengan Ular Raksasa, 9) pantang menyerah di akhir pertarungan sehingga membawa kemenangan, 10) tegar sebagai bentuk ketangguhannya setelah memenangkan pertempuran, 11) cinta tanah air diungkapkan setelah memenangkan pertarungan karena ingin kembali hidup di negerinya, 12) tanpa pamrih sebagai wujud sikap mengutamakan kepentingan umum di atas kepentingan pribadi diungkapkan pascapertarungan dan saat diberi hadiah tiga jenis ikan oleh Buaya Pulau Seram, dan 13) rela berkorban bahkan nyawa sekali pun ditunjukkan dengan meninggalnya Sang Raja dalam perjalanan pulang menuju Pulau Haruku.

Dari rangkuman di atas, maka nilai moral yang disampaikan melalui tokoh Buaya Learisa Kayeli yaitu "janganlah takut membela kebenaran/menumpas kezaliman meskipun nyawa menjadi taruhannya supaya tercipta kehidupan yang harmonis dan tenteram".

\subsection{Buaya Pulau Seram}

Rangkuman perwatakan tokoh Buaya Pulau Seram, antara lain: 1) mengutamakan gotong royong dan kebersamaan ditunjukkan dalam menjalani kehidupan sehari-hari di Pulau Seram, 2) cinta tanah air saat Ular Raksasa datang mengusik, 3) saling menghargai pendapat orang lain tercermin dalam musyawarahmufakat yang dilakukan ketika hendak meminta bantuan Sang Raja Sungai Learisa Kayeli, 4) religius diungkapkan saat mereka berdoa agar Sang Raja diberikan kekuatan mengalahkan Ular Raksasa, 5) menghormati dan mengagumi sosok Raja Learisa Kayeli atas keberhasilannya mengalahkan Ular Raksasa, 6) berempati dan peduli dengan kondisi Sang Raja ketika hendak kembali ke Pulau Haruku pascapertarungan, 7) tau balas budi sebagai bentuk upaya saling menghargai dengan memberi bekal tiga jenis ikan kepada Raja Learisa Kayeli yang 
hendak kembali ke Pulau Haruku, dan 8) bersahabat ditunjukkan ketika Sang Raja menerima tanda persahabatan dari mereka.

Dari rangkuman di atas, maka nilai moral yang disampaikan melalui tokoh Buaya Pulau Seram yaitu "hargailah orang yang telah berjasa dalam (menyelamatkan) hidupmu supaya terjalin persaudaraan yang abadi sampai akhir hayat".

\subsection{Ular Raksasa}

Rangkuman perwatakan tokoh Ular Raksasa, antara lain: 1) pengusik kedamaian sekaligus mengusir hewan lain ditunjukkan dengan kedatangannya di Pulau Haruku dan 2) sombong saat bertarung dengan Raja Learisa Kayeli sehingga berakhir tragis, tewas ditangan Sang Raja.

Dari rangkuman di atas, maka nilai moral yang disampaikan melalui tokoh Ular Raksasa yaitu "janganlah suka mengganggu ketenangan hidup orang lain supaya tidak bernasib buruk di kemudian hari”.

\subsection{Buaya Muda}

Rangkuman perwatakan tokoh Buaya Muda, antara lain: 1) berdaya tahan tercermin dari kemandiriannya dalam mempertahankan hidup tanpa orang tua, 2) determinatif dalam menentukan kelanjutan hidupnya diungkapkan setelah ia pandai berenang dan mencari makan sendiri, 3) berani diungkapkan dalam perjalanan menuju Pulau Haruku, 4) rasa ingin tahu yang tinggi dalam mencari jalan pulang diungkapkan ketika tersesat di Pantai Passo, 5) pantang menyerah diungkapkan mencari informasi jalan pulang menuju Pulau Haruku, 6) kritis diungkapkan ketika ia memutuskan untuk berhenti di tengah perjalanan dari Pantai Passo menuju Pulau Haruku karena ada perasaan mengganjal dalam hatinya, 7) peduli kepada pengikutnya diungkapkan ia menyadari bahwa ikan parang-parang tidak turut serta dalam rombongan, 8) menghayati kuatnya rasa kebersamaan diungkapkan ketika ia menyadari bahwa ikan parang-parang tidak turut serta dalam rombongan karena tertinggal di Pantai Passo, 9) gigih dalam perjalanan pulang diungkapkan setelah ia memutuskan untuk melanjutkan perjalanan ke Pulau Haruku tanpa ikan parang-parang, 10) ramah diungkapkan ketika sudah sampai di Pulau Haruku dengan menyapa siapa pun yang berada di sekitar Sungai Learisa kayeli, 11) bertanggung jawab dengan menjaga ikan lompa dan ikan make atas gangguan makhluk lain selama berada di Pulau Haruku, 12) tangguh diungkapkan ketika ia beranjak dewasa, 13) bersahabat diungkapkan ketika ia dewasa dan melanjutkan teladan baik dari ibunya, yaitu menolong dan akrab dengan warga, dan 14) kooperatif dengan warga diungkapkan di bagian akhir cerita ini, yaitu buaya menjaga warga dan warga juga menjaga buaya.

Dari rangkuman di atas, maka ada dua nilai moral yang disampaikan melalui tokoh Buaya Muda, yaitu "jangan pernah menyerah dalam berusaha supaya impianmu bisa tercapai" dan "berperangailah dengan baik terhadap orang lain supaya kamu bisa diterima oleh siapa pun dan di mana pun termasuk di lingkungan baru sekali pun”.

\subsection{Tiga Jenis Ikan}

Rangkuman perwatakan tokoh ikan lompa, ikan make, dan ikan parang-parang, antara lain: 1) amanah tercermin dalam kesetiaan mereka terhadap Sang Raja dan Buaya Muda dalam perjalanan menuju Pulau Haruku dan 2) dapat diandalkan diungkapkan saat mereka berkembang biak dengan jumlah yang melimpah sehingga menjadi ikan andalan warga setempat.

Dari rangkuman di atas, maka nilai moral yang disampaikan melalui tokoh Tiga Jenis Ikan yaitu "bersabarlah dalam menghadapi rintangan kehidupan supaya buah dari kesabaran itu bisa bermanfaat bagi orang lain". 


\subsection{Manusia}

Rangkuman perwatakan manusia ditunjukkan oleh: 1) Warga Pulau Haruku yang peduli lingkungan sekitar agar tidak tercemar sampah, 2) Warga Pulau Haruku yang tau balas budi sebagai bentuk upaya saling menghargai dilakukan dengan menyematkan cincin ke jari Sang Buaya sebagai tanda terima kasih atas kebaikan Sang Buaya, 3) Warga Waai yang berempati diungkapkan saat Sang Raja terdampar di Pantai Waai karena kelelahan, dan 4) Warga setempat yang adil memanfaatkan kekayaan alam di sekitarnya ditunjukkan dengan memanfaatkan keberlimpahan ikan sesuai dengan kebutuhannya.

Dari rangkuman di atas, maka nilai moral yang disampaikan melalui tokoh Manusia yaitu "bersikap bijaklah terhadap lingkungan sekitar supaya tercipta keseimbangan alam yang sehat sehingga bisa memberikan keuntungan bagi umat manusia".

\section{PENUTUP}

Berdasarkan pembahasan di atas, dari keenam tokoh cerita dapat disimpulkan bahwa sebagian besar tokoh dalam cerita rakyat Buaya Learisa Kayeli berkualifikasi baik dari awal sampai akhir, yaitu Buaya Learisa Kayeli, Buaya Pulau Seram, Buaya Muda, Tiga Jenis Ikan, dan Manusia. Adapun tokoh dengan kualifikasi jahat dari awal sampai akhir adalah Ular Raksasa. Watak tokoh yang diungkapkan dengan cara uraian lebih dominan daripada cara dramatik. Maka dari itu, hal ini sesuai dengan kaidah dasar teori sastra anak Burhan Nurgiyantoro.

Dari keenam tokoh tersebut, masing-masing tokoh mengandung satu nilai moral, kecuali tokoh Buaya Muda mengandung dua nilai moral. Maka dari itu, ada tujuh nilai moral yang disampaikan pengarang melalui tokoh cerita tersebut, antara lain: (1) janganlah takut membela kebenaran/menumpas kezaliman meskipun nyawa menjadi taruhannya supaya tercipta kehidupan yang harmonis dan tenteram; (2) hargailah orang yang telah berjasa dalam (menyelamatkan) hidupmu supaya terjalin persaudaraan yang abadi sampai akhir hayat; (3) janganlah suka mengganggu ketenangan hidup orang lain supaya tidak bernasib buruk di kemudian hari; (4) jangan pernah menyerah dalam berusaha supaya impianmu bisa tercapai; (5) berperangailah dengan baik terhadap orang lain supaya kamu bisa diterima oleh siapa pun dan di mana pun termasuk di lingkungan baru sekali pun; (6) bersabarlah dalam menghadapi rintangan kehidupan supaya buah dari kesabaran itu bisa bermanfaat bagi orang lain; dan (7) bersikap bijaklah terhadap lingkungan sekitar supaya tercipta keseimbangan alam yang sehat sehingga bisa memberikan keuntungan bagi umat manusia.

\section{DAFTAR PUSTAKA}

Ampere, Taufik. (2010). Pengajaran Sastra. Bandung: Widya Padjadjaran.

Asrif. (2016). Buaya Learisa Kayeli. Jakarta: Badan Pengembangan dan Pembinaan Bahasa Kemendikbud.

Badudu, J.S. dan Sutan Mohammad Zain. (1994). Kamus Umum Bahasa Indonesia. Jakarta: Pustaka Sinar Harapan.

Hasan, Nita Handayani. (2016). "Cerita Rakyat Jaka Tarub dan Air Tukang: Suatu Kajian Sastra Bandingan" dalam Jurnal Totobuang Volume 4 Nomor 2. Ambon: Kantor Bahasa Maluku.

Hasan, Nita Handayani. (2016). "Penerapan Teori Vladimir Propp pada Cerita Rakyat Ikan Lompa" dalam Jurnal Totobuang Volume 4 Nomor 1. Ambon: Kantor Bahasa Maluku.

Hasan, Nita Handayani. (2017). "Motif dan Tipe dalam Cerita Rakyat Kepulauan Aru" dalam Jurnal Totobuang Volume 5 Nomor 1. Ambon: Kantor Bahasa Maluku. 
Kastanya, Helmina. (2020). “Analisis Nilai Budaya dalam Cerita Rakyat Maluku Air Tukang" dalam Jurnal Totobuang Volume 8 Nomor 2. Ambon: Kantor Bahasa Maluku.

Nurgiyantoro, Burhan. (2019). Sastra Anak. Yogtakarta: Gadjah Mada University Press.

Ratna, Nyoman Kutha. (2013). Teori, Metode, dan Teknik Penelitian Sastra. Yogyakarta: Pustaka Pelajar.

Sarumpaet, Riris K. (2017). Pedoman Penelitian Sastra Anak. Jakarta: Yayasan Pustaka Obor Indonesia.
Sumardjo, Jakob dan Saini K.M. (1988). Apresiasi Kesusastraan. Jakarta: Gramedia.

Tim Penyusun. (2010). Kebijakan Nasional Pembangunan Karakter Bangsa Tahun 2010--2025. Jakarta: Pemerintah Republik Indonesia.

Tim Penyusun. (2016). KBBI V 0.4.0 Beta. Jakarta: Badan Pengembangan Bahasa dan Perbukuan Kemendikbud.

Zakiyah, Qiqi Yuliati dan Rusdiana. (2014). Pendidikan Nilai. Bandung: Pustaka Setia. 
